\title{
EDUCAÇÃO CORPORATIVA: A PROPOSTA EMPRESARIAL NO DISCURSO E NA PRÁTICA
}

\section{Daniele Cruz*}

RESUMO: Análise do modelo de Educação Corporativa adotado pela Leader Magazine e as expectativas dos funcionários sobre suas trajetórias em termos de apropriação de conhecimentos e crescimento profissional. Um estudo de caso crítico, com análise documental e entrevistas. O referencial abordou as mudanças que influenciaram o cenário global e a influência do empresariado sobre as políticas de educação nas três últimas décadas. Nos resultados, vemos que, embora a empresa, no discurso, apresente a Escola de Varejo como uma política formal de EC, na prática se reduz a ações isoladas, com cursos na maioria comportamentais. A proposta voltou-se para objetivos estratégicos, focando no mercado, não levando em conta os interesses dos funcionários. Apesar de a empresa considerar sua política relevante, os funcionários desconhecem a EC como um modelo educacional e encaram as ações como cursos pontuais, acreditando, porém, que o trabalho desenvolvido pela empresa de fato contribui para o seu crescimento.

Palavras-Chave: Educação Corporativa; Trabalho e Educação.

\section{CORPORATE EDUCATION:}

\section{A COMPANY PROPOSAL IN THEORY AND PRACTICE}

ABSTRACT: To analyze the Corporate Educational (CE) model adopted by Leader Magazine and the employees expectations about their development due to knowledge acquisition and professional improvement. A critical case study, with documental analysis and interviews. The referential discussed the changes occurred in the last three decades that influenced the global scenario and the influence of business people upon educational policies. As a result, we noticed that, although companies speak of the Retail Education as a formal CE policy, in practical terms it is reduced to a few isolated actions, offering behavioral courses on its majority. The proposal was aimed at strategic objectives, focusing on the market and without considering the interests of the employees. Although the company regards its policies as relevant, the employees have failed to recognize the $\mathrm{CE}$ as an educational model and regard the actions as specific courses, believing however, that the work developed in the company really contributes for their personal and professional development.

Keywords: Corporate Education, Work and Education.

\footnotetext{
* Mestre em Educação pela Universidade Estácio de Sá (UNESA); Membro do Grupo de Pesquisa em Trabalho e Educação da Fundação Oswaldo Cruz (FIOCRUZ); Professora da Rede Estadual do Rio de Janeiro. E-mail: andreedan@ig.com.br
} 


\section{Introdução}

As mudanças ocorridas na economia nos últimos anos nos remete também às mudanças no campo educacional. Em função do quadro existente, o país precisa se desenvolver e investir em tecnologia e educação. Como resposta à crise capitalista que se inicia nos anos 1970, no plano internacional, e as mudanças que ocorrem na sociedade como consequência, várias estratégias vêm sendo adotadas pelo empresariado, ao longo dos anos, no sentido de alinhar economia e educação em prol dos objetivos da produtividade. Entre estas está a educação corporativa.

No contexto atual, em que o discurso hegemônico é o da valorização do homem, do "capital intelectual" (NONAKA; TAKEUCHI, 1997), e da chamada "sociedade do conhecimento" (SVEIBY, 2001), interessa analisar criticamente o papel central da educação e, nessa mesma via, por um lado, a intenção das empresas em assumirem um papel educacional que até então cabia ao Estado e às escolas, e, por outro, ouvir o trabalhador, "objeto" desse processo, com suas expectativas, seu real retorno.

Este artigo tem como objetivo analisar, no campo do trabalho e da educação, o modelo de educação corporativa adotado por uma empresa brasileira privada de médio porte, do ramo varejista, e as expectativas dos funcionários que participaram dos programas educacionais sobre suas trajetórias. São discutidas, igualmente, as mudanças ocorridas nas últimas décadas, que definitivamente influenciaram todo o cenário global; são abordados o papel e a influência que o empresariado atualmente tem sobre as ações de educação, assim como o modelo de educação corporativa adotado nas empresas.

\section{Mudanças no mundo do trabalho e implicações para a educação}

O contexto de mudanças no mundo do trabalho que vivenciamos na sociedade contemporânea tem suas origens na crise dos anos 70 do século passado. A era do capitalismo monopolista, entre 1945 e 1975, chamada "Era de Ouro" (HOBSBAWM,1995), caracterizada pelo padrão de acumulação fordista, com produção em série, consumo de massa, organização prescrita do trabalho, com trabalho fragmentado e separação entre elaboração e execução, entra em crise nas décadas que se seguiram. 
Até os anos 1970, vigorava o modelo de organização fabril, com base no fordismo-taylorismo, e este padrão de acumulação do capital, a partir da crise do petróleo, em aproximadamente 1973, precisou se reestruturar, buscando novas formas de organização da produção e do trabalho. Esse esforço de reorganização econômica, política e ideológica do capital resulta em um novo modelo de acumulação flexível, que se apoia na flexibilidade dos processos de trabalho, produtos e padrões de consumo, e envolve várias mudanças, como explicita Frigotto (1995, p. 144):

Os novos conceitos abundantemente utilizados pelos homens de negócio e seus assessores - globalização, integração, flexibilidade, competitividade, qualidade total, participação, pedagogia da qualidade e defesa da educação geral, formação polivalente e "valorização do trabalhador" - são uma imposição das novas formas de sociabilidade capitalista tanto para estabelecer um novo padrão de acumulação quanto para definir as formas concretas de integração dentro da nova reorganização da economia mundial. (FRIGOTTO, 1995, p. 144)

Esse novo padrão de acumulação serve assim como pano de fundo para que a sociedade capitalista instaure suas novas bases econômicas, políticas e ideológicas, demandando um novo tipo de trabalhador, mais qualificado, mais flexível, mais envolvido com a produção, com as chamadas novas competências (DELUIZ, 1996; 2001), reforçando ainda mais a exclusão social daqueles que não adquiriram essas habilidades e competências.

O modelo de educação profissional anterior, ao ter como horizonte produtivo o fordismo-taylorismo, orientava-se para a qualificação operacional adequada àquela forma de organização técnica do trabalho; já no modelo de acumulação flexível, o trabalhador será valorizado ou não no mercado por suas competências.

Bianchetti (2001) fornece elementos para descrermos da homogênea intelectualização das novas formas de trabalho, ao comentar o esforço de objetivação, expropriação, despersonalização e padronização dos gestos e atitudes, a apropriação e a sistematização do conhecimento tácito do trabalhador. Santos (2004, p. 10) ratifica essas ideias ao apontar que "Desmascara-se o hipotético pacto capital-trabalho do fordismo, mas apela-se para o engajamento afetivo do trabalhador na organização".

Com a mudança do padrão de acumulação, desenvolve-se a Teoria do Capital Intelectual. No paradigma anterior, vigorava a Teoria do 
Capital Humano (TCH), cujo ideário residia na relação de proporção entre escolaridade e renda, na causalidade entre patrimônio escolar e salário. O capital humano era considerado como um estoque de habilidades, atitudes e valores e de saúde do trabalhador, aliado às metas, objetivos, missão e cultura da empresa. Segundo a Teoria do Capital Humano, quanto maior a educação, a escolaridade, maior a possibilidade de aumento da renda do indivíduo e, consequentemente, do desenvolvimento de uma nação (SCHULTZ, 1973). Em outras palavras, quanto maior a escolarização, melhor a condição de vida devido ao aumento de sua renda, já que, mais qualificado, o sujeito tem melhor desempenho no mercado de trabalho e maiores ganhos. Na segunda teoria, a Teoria do Capital Intelectual (TCI), são mais importantes as habilidades pessoais, subjetivas. Hoje, tenta-se objetivar, expropriar e controlar o "conhecimento tácito", que, segundo Nonaka e Takeuchi (1997, p. 33), “é altamente pessoal, por ser de difícil formalização, sua transferência para os outros também á árdua (...). Consiste de modelos mentais, crenças e perspectivas tão arraigadas que são tidas como algo certo, não sujeitas a fácil manifestação.” Sendo possível o controle do conhecimento tácito, são asseguradas, também, a produção e a circulação do conhecimento no âmbito da própria empresa.

Para Santos (2004), o surgimento da Teoria do Capital Intelectual associada ao movimento da educação corporativa revela mais do que a simples retomada de uma elaboração teórica gerada em uma fase hegemônica do capital, pois, ao analisar as duas teorias, é latente a diferença da participação do Estado.

Segundo a autora, a Teoria do Capital Humano, que tinha como ponto central a alocação da atividade educacional como componente da produção, vigorava o Estado de Bem Estar social e o capital atribuía ao poder público o papel de protagonista das ações educativas. Hoje, na chamada Teoria do Capital Intelectual, no contexto do Estado mínimo neoliberal, o capital assume para si a função de dirigente de projetos educacionais materializados em programas de educação corporativa.

A gestão organizacional, orientada pela ótica hegemônica, também tem se esforçado por construir o espírito adesista no âmbito interno das organizações. Éboli (2004) e Meister (1999) retratarão esse discurso como fundamental no modelo de educação para o atual padrão de acumulação.

Para Santos (2004), hoje existem apelos ao novo papel do líder, que deve motivar e sensibilizar, diferentemente do supervisor fordista- 
taylorista, que tinha a função de controlar. Essa relação de cooptação, para a autora, revela uma tentativa de controle da subjetividade do trabalhador. Como aponta Harvey (1992, p. 119):

A disciplinação da força de trabalho para os propósitos de acumulação do capital - um processo como vou me referir, de modo geral, como "controle do trabalho" - é uma questão muito complicada. Ela envolve, em primeiro lugar, alguma mistura de repressão, familiarização, cooptação e cooperação, elementos que têm de ser organizados não somente no local de trabalho como na sociedade como um todo. A socialização do trabalhador nas condições de produção capitalista envolve o controle social bem amplo das capacidades físicas e mentais. A educação, o treinamento, a persuasão, a mobilização de certos sentimentos sociais (a ética do trabalho, a lealdade aos companheiros, o orgulho local ou nacional) e propensões psicológicas (a busca da identidade através do trabalho) (...) desempenham um papel e estão claramente presentes na formação de ideologias dominantes cultivadas pelos meios de comunicação de massa, pelas instituições religiosas e educacionais, pelos vários setores do aparelho do Estado... (HARVEY, 1992, p. 119)

\section{Empresariado e educação}

Rodrigues (1998) e Bianchetti (2005) apontam o interesse do capital na educação e discutem as relações entre empresa e escola nas últimas décadas, o que nos permite entender esse caminhar ao longo dos anos. Nas décadas de 1960/1970, a empresa demandava à universidade e às escolas técnicas os profissionais de que precisavam, principalmente no predomínio do paradigma taylorista/fordista, segundo o qual muitos eram formados no SENAI e no CEFET, por exemplo.

A partir dos anos 1980, as empresas organizam setores de recursos humanos, visando, entre outros aspectos, ao treinamento e ao desenvolvimento dos funcionários em questões pontuais, objetivando adaptá-los às mudanças técnicas, gerenciais e organizacionais. Um terceiro momento, mais recente, a partir dos anos 1990, caracteriza-se por iniciativas da própria empresa, adotando escolas públicas, aproximando-se da comunidade (como o programa "amigos da escola", amplamente divulgado pela mídia) e ainda pela criação de escolas em seu interior, via parceria com estados e municípios, contando com professores públicos para formar seus funcionários, como, por exemplo, o projeto "Escola na Fábrica” (QUARTIERO; BIANCHETTI, 2005). 
Sobre essa aproximação do empresariado com as escolas, Fidalgo (1999, p. 147-148) constata:

Na sua implementação, eles sugerem o estabelecimento estratégico de parcerias entre as empresas e as escolas públicas, que na realidade pode vir a representar a perda da autonomia da escola face aos interesses empresariais. É interessante notar que quando falam de parceria, os empresários usam a expressão "adotar escolas", o que sugere a colocação destas instituições sob custódia e, possivelmente sob o jugo do adotante. É como se a escola ganhasse um pai que diz sempre saber exatamente o que é melhor para seus filhos. (FIDALGO, 1999, p. 147-148)

Além dos investimentos em tecnologias, é fundamental para as empresas o investimento no campo social, e como a educação é considerada um dos pilares para o desenvolvimento, essa é uma das áreas e que as empresas vêm atuando efetivamente, das mais variadas formas.

(...) dada a carência educacional da força de trabalho brasileira e os problemas institucionais para reverter esse quadro, tornou-se necessário que as empresas investissem recursos em áreas tradicionalmente de responsabilidade do Estado. Isto é, apesar do custo, [...] as empresas líderes [...] resolveram o problema da carência de mão-de-obra. (SENAI, DESAFIOS E OPORTUNIDADES, 1994, p. 33 apud RODRIGUES, 1998, p. 119)

Atualmente, a própria empresa cria suas escolas e universidades - as chamadas "Universidades Corporativas", para garantir uma educação sob medida (MEISTER, 1999; EBOLI, 2004). Sob a medida do capital, evidentemente, mas essa educação, por sua vez, segundo Santos (2004), não prescinde do Estado financiador, ou seja, as empresas querem determinar o modelo de educação, mas não querem arcar sozinhas com esse "investimento". querem que o Estado também pague por isso, seja diretamente seja por meio de Secretarias de Educação, por exemplo, com programas como o PROUNI - "Universidade para todos" - e por contrapartida fiscal.

Sob a influência das agências internacionais, a políticas educacionais são desenvolvidas objetivando o fortalecimento da reprodução do capital. Ao mesmo tempo, cada vez mais torna-se evidente o quanto vários administradores - estaduais e municipais - instituem mecanismos voltados diretamente à diminuição da publicização do espaço público, abrindo para um conjunto 
maior de instituições privadas, tais como escolas privadas, ONGs, etc., a possibilidade de disputar o fundo público. Medidas estas que representam a diminuição do controle do estado sobre a educação e, conseqüentemente, a privatização do sistema educacional. (OLIVEIRA, 2001, p.5)

Manangão (2003), ao analisar o cenário atual, aponta que, no modelo neoliberal, faz-se apologia à privatização, transferindo-se para a iniciativa privada a responsabilidade de atender às demandas que o Estado não administra ou soluciona. Como diz Santos (2004), se o mercado interfere na educação e se se julga autoridade para planejar essas políticas, a educação corporativa tende a se estabelecer como um modelo que se origina do mercado e a ele se volta. Surge, assim, como forma de mercantilização da educação, que, segundo a autora, significa a ausência do papel do Estado em oferecer educação profissional de qualidade a todos. Significa um ajuste restrito da educação profissional às leis do mercado, implicando um caráter reducionista da mesma. Resta saber que papel essa educação vai assumir a partir das novas formas de organização do trabalho.

\section{Educação corporativa:}

histórico, objetivos, concepções, métodos

Utiliza-se o termo "educação corporativa" desde a década de 1950, quando a General Eletric lançou a Crotonville (1955) (QUARTIERO; BIANCHETTI, 2005). Sua origem é nos Estados Unidos, quando muitas empresas, determinadas a tornarem-se líderes empresariais na economia global, lançaram a educação corporativa com veículo para ganhar vantagem competitiva (MEISTER, 1999). Nessa década, só nos Estados Unidos, essas instituições passaram de 400 para 2000, e estimativas indicam que, no Brasil, temos pelo menos 50 das chamadas "universidades corporativas".

Para a autora, que é uma das precursoras da fase contemporânea do movimento, a educação corporativa é mais do que um processo, é um "trabalho em andamento", e a define como um "guarda-chuva estratégico para o desenvolvimento e a educação de funcionários, clientes e fornecedores, buscando otimizar as estratégias organizacionais, além de um laboratório de aprendizagem para a organização e um pólo de educação permanente" (MEISTER, 1999, p. 8). 
Segundo Meister (1999), o modelo de educação corporativa é sustentado por cinco grandes forças do cenário global: o surgimento da educação por processos, horizontalizada e flexível; a emergência da gestão do conhecimento; a volatilidade da informação e a obsolescência do conhecimento; o foco na empregabilidade: educar para o trabalho, não para o emprego; e a mudança no foco da educação geral.

As empresas mais bem-sucedidas, ao invés de esperar que as escolas tornem seus currículos mais relevantes para a realidade empresarial, resolveram percorrer o caminho inverso e trouxeram a escola para dentro da empresa. Abandonaram o paradigma de que a educação seria um capítulo da responsabilidade social da empresa e passaram de forma muito pragmática a entender que o diferencial decisivo de competitividade reside no nível de capacitação em todos os níveis de seus funcionários, fornecedores principais, clientes e até mesmo membros da comunidade onde atuam. (MEISTER, 1999, p. xv)

A autora afirma que a educação corporativa é uma iniciativa organizacional que visa a garantir um processo contínuo e estruturado de aprendizagem vinculada a objetivos estratégicos. Ela pode ser definida como um sistema de desenvolvimento de pessoas, pautado pela gestão por competências, cujo papel é o de servir de ponte entre o aprimoramento pessoal e a estratégia de atuação da instituição. Constitui-se numa forma inteligente de as organizações assumirem o domínio do negócio de educação e treinamento, garantindo o melhor aproveitamento de recursos e vinculando os programas de treinamento à produção de competências necessárias para as estratégias do negócio.

Para Meister (1999), o objetivo da educação corporativa é obter um controle mais rígido sobre o processo de aprendizagem, vinculando de maneira mais estreita os programas de aprendizagem a metas e resultados estratégicos reais da empresa. "A essência da organização do século XXI está em trabalhadores com conhecimento culturalmente diverso. Nela trabalho e aprendizagem são essencialmente a mesma coisa, com ênfase no desenvolvimento da capacidade do indivíduo de aprender" (MEISTER, 1999, p. 2). E completa que por educação corporativa entende-se um conjunto de práticas educacionais contínuas com visão estratégica de negócios, que possibilitam maior entrosamento do capital intelectual de uma organização.

Vianna (2004, p. 1) salienta que, na expressão universidade corporativa, o uso do termo "corporativo" significa que ela é vinculada a uma 
corporação e que serviços educacionais não são sua atividade-fim. Da mesma forma, o termo "universidade" não deve ser entendido dentro do contexto do ensino superior, o qual designa a educação de estudantes e o desenvolvimento de pesquisa em várias áreas do conhecimento. Para o autor, na universidade corporativa "a educação, os programas de capacitação, o desenvolvimento de competências e as pesquisas estarão relacionadas sempre à área do negócio da empresa e fundamentalmente ao seu posicionamento estratégico" (VIANNA, 2004, p. 1).

Para Meister (1999, p. 35), entretanto, o uso dessa metáfora (o termo universidade) cria a imagem da grande finalidade da iniciativa da educação ou ensino corporativo, que é prometer aos participantes e a seus patrocinadores que a universidade corporativa irá prepará-los para o sucesso no trabalho atual e na carreira futura. Segundo a autora, o uso desse termo "ajudou a dar ao programa a marca de que ele precisava para decolar".

A educação corporativa é um conceito que emerge no discurso empresarial como uma possibilidade ao processo de aprendizagem contínua, que tanto se espera do trabalhador; uma tentativa de preencher lacunas e descompassos causados pelo ensino e pelas universidades que o capital julga "tradicionais". Entretanto, não há dúvidas de que isso torna mais explícita a mercantilização da educação, indo ao encontro das prescrições do Banco Mundial a respeito de como devem ser discutidas, encaminhadas e elaboradas as questões relacionadas à educação (QUARTIERO; BIANCHETTI, 2005).

Santos (2004, p. 3) compreende "o surgimento desse modelo de formação como a estratégia atualmente considerada a mais adequada pelo capital para a reprodução da força de trabalho", explicitada nas suas tentativas, ao longo dos anos, de se apropriar da educação. Com a educação corporativa, "trabalho e aprendizagem sobrepõem-se nas empresas" (QUARTIER; BIANCHET'TI 2005, p. 10), no entanto, os autores enfatizam:

De espaços e tempos claramente delimitados, com especificidades que as caracterizavam - a escola concebida como lócus de ensino e de aprendizagens; a empresa como campo de aplicação de conhecimentos, adquiridos em outro tempo e lugar - passa-se para uma situação onde o lócus espaço-temporal de ensino e de aprendizagem e o da produção de bens materiais e bens intangíveis já não conhecem mais as rígidas delimitações que caracterizavam a relação entre essas instituições. (QUARTIER; BIANCHET'TI 2005, p. 10) 
Como vimos, são comuns, na educação corporativa, os argumentos de desvalorização da educação tradicional, por não se voltar para a formação de competências para o trabalho, mas Santos $(2004$, p. 9) ressalta as contradições no discurso empresarial:

O discurso dominante propaga a exigência de maior escolaridade, mas diz considerar, na avaliação da força de trabalho, as competências, não a qualificação; propaga a necessidade de competências, mas novas formas de trabalho não exigem necessariamente nem maior qualificação, nem maior competência; divulga amplamente que o novo trabalhador deverá ser capaz de lidar com os eventos, deflagradores das competências, definidos essencialmente por seu caráter de imprevisão e criatividade no trato, mas investe recursos inestimáveis no controle e padronização das ocorrências do trabalho; afirma formalmente a valorização das competências, que pertencem à esfera privada do indivíduo, mas persegue incansavelmente formas cada vez mais elaboradas de objetivar, expropriar e padronizar o conhecimento tácito, gerando o paradoxo da complexificação do trabalhador coletivo e simplificação e esvaziamento do trabalhador individual, que ao ser descartado, não deixa marcas pessoais, pois seu valor já foi agregado à mercadoria e ao processo coletivo de trabalho. (SANTOS, 2004, p. 9)

\section{A educação corporativa entre o discurso e a prática: estudo de caso da Leader Magazine}

Em pesquisa quanti-qualitativa, realizada na Leader Magazine ${ }^{3}$, foram analisados os dados baseados em entrevistas com trabalhadores de lojas, setores e cargos variados. Essas entrevistas abrangeram 26 funcionários que correspondem a 1\% do corpo funcional de toda a empresa, 2\% dos funcionários do Grande Rio e 7,2\% dos funcionários da região de Niterói e São Gonçalo, onde está estabelecida a sede da empresa e onde a pesquisa foi realizada. Além das falas dos funcionários, buscou-se analisar a fala da empresa, em Gouvêa (2004), e em entrevistas com o pessoal de Recursos Humanos, além das informações disponibilizadas no site da empresa e no material fornecido pela organização a respeito de sua cultura organizacional e da implantação da ELEVAR (Escola Leader de Varejo).

Para todos os funcionários da empresa, de qualquer cargo ou setor, a exigência mínima de escolaridade é o ensino médio completo. Por se tratar de comércio varejista, foram entrevistados somente o pessoal de 
loja, que corresponde a 95\% da empresa, com renda variada entre $\mathrm{R} \$ 360,00$ e $\mathrm{R} \$ 1300,00$ mensais.

Foram entrevistados $50 \%$ de funcionários homens e $50 \%$ de mulheres, coincidentemente. O nível de escolaridade é basicamente o ensino médio, com apenas 7,69 \% dos entrevistados com ensino superior completo. Quanto a esse aspecto, Invernizzi (2000) chama a atenção em relação a como a exigência de aumento de escolaridade se difundiu na última década, considerando, entretanto, que esse aumento não é apenas o resultado da demanda de um novo perfil educacional, mas também resultado da oferta da força de trabalho disponível.

Como a ELEVAR (Escola Leader de Varejo) foi criada em 1999, procuramos entrevistar preferencialmente funcionários com mais tempo de casa, que pudessem ter tido oportunidades de passar pelos processos e que pudessem ter suas trajetórias de fato analisadas, daí o índice de $80,77 \%$ de pessoas entrevistadas com mais de cinco anos de casa. A média geral de tempo de casa acima de cinco anos, levando-se em conta toda a organização, está na faixa de 40\%. O Departamento de RH frisou inclusive que a empresa passou dez anos sem contratar funcionários novos para cargos de chefia, pois sempre priorizava promover os antigos.

Hierarquicamente, na atualidade uma loja está dividida entre os cargos de gerente, apenas um em cada unidade, supervisor (de área, caixa ou crédito), atendente sênior (de área ou caixa), atendente pleno e atendente júnior. Nesta questão, o percentual de entrevistas por cargo/função foi variado.

Ao serem indagados sobre o fato de a empresa possuir algum tipo de programa educacional, 38,46 \% dos entrevistados afirmaram não saber se a empresa tinha programas educacionais, $11,53 \%$ afirmaram existir esses programas, 23,08\% citaram a ELEVAR diretamente e 26,93\% falaram sobre incentivos e parcerias externas, com descontos para funcionários para completarem o ensino médio e cursarem a graduação.

É importante ressaltar a ideia do trabalho e da aprendizagem sobrepondo-se nas empresas, como enfatiza criticamente Bianchetti (2005, p. 10):

Tendo como ponto de partida uma formação básica, o indivíduo é estimulado ou compelido, pelas atuais transformações do mundo do trabalho, a complementar seus estudos dentro e fora da empresa, o que recebe diferentes denominações (formação continuada, educação permanente, formação ao 
longo da vida), mas todas com o mesmo sentido: a necessidade de aprendizagem constante. (BIANCHET'TI, 2005, p. 10)

Sobre educação corporativa, 53,85 \% dos funcionários entrevistados não conhecem o termo, 26,92\% já ouviram falar e somente 19,23\% afirmaram saber do que se trata. Ainda, 42,31\% dos funcionários entrevistados não sabem se a prática da educação corporativa faz parte da Leader Magazine, sendo que 23,08\% acham que sim e 34,61\% afirmam que faz. Do total das respostas afirmativas, somente $3,85 \%$ citam a ELEVAR como responsável por essa atividade na organização, outros $96,15 \%$ não teceram comentários a respeito da participação da ELEVAR nesse processo.

Perguntamos diretamente aos funcionários se conheciam o trabalho da ELEVAR, se sabiam o que ela fazia: 57,69\% dos entrevistados afirmaram conhecer, 23,08\% já ouviram falar e 19,23\% afirmaram não saber qual o propósito da ELEVAR. A maioria dos funcionários que de fato conheciam a ELEVAR era de níveis mais altos na hierarquia, 100\% dos gerentes e supervisores conheciam o trabalho dessa área da empresa, remetendo-nos à alusão de escola dualista, em Aranha (1989), que tinham objetivos diferentes; para a elite, uma escola de formação que pode se estender a níveis superiores, e, para os trabalhadores, rudimentos do ler e escrever e encaminhamentos para a profissionalização.

No aspecto treinamento, $38,46 \%$ participaram de mais de dez cursos, 26,93\% participaram de mais de cinco cursos, 19,23\% estiveram presentes em mais de três cursos e somente 15,38\% participaram apenas de até três cursos, o que sinaliza o investimento feito nesse sentido pela organização e também percebido pelos funcionários.

No que diz respeito aos objetivos desses cursos, $50 \%$ dos entrevistados disseram que era para desenvolvimento e melhora do desempenho, 30,77\% afirmaram ser sobre atendimento a clientes. Ainda 7,69\% dos funcionários entrevistados falaram sobre o curso de prevenção de perdas, esse mesmo índice (7,69\%) informou serem os treinamentos corporativos sobre valores da empresa e apenas 3,85\% falaram que o assunto era vendas. Desse total, $61,54 \%$ deram respostas ligadas a motivação, liderança, autoestima, que são considerados treinamentos comportamentais. Outros 38,46\% não pontuaram especificamente nenhum tema.

Com relação à relevância dos temas, o objetivo da pergunta foi, de certa forma, levantar, de fato, o que ficou mais marcado para os fun- 
cionários nos treinamentos de que participaram, então 15,38 \% citaram o tema da liderança, também 15,38\%, aspectos relacionados a falar, ouvir, expressar (comunicação em geral); 19,23\% falaram da autoconfiança; e 15,38\%, de responsabilidade e respeito. Outros 34,63\% foram respostas pulverizadas sobre percepção do cliente, união e ética.

Assim, podemos observar que, no total, mais de $65 \%$ comentaram aspectos basicamente comportamentais. Não foi observado nenhum aspecto técnico, científico ou de formação profissional como resposta à questão sobre o que aprenderam de mais importante para o seu trabalho nos cursos de que participaram. Ainda assim, 96,15\% dos funcionários entrevistados afirmaram gostar de participar dos treinamentos, e uma única pessoa $(3,85 \%)$ comentou suas dificuldades nessa questão. Também $96,15 \%$ afirmaram categoricamente que os programas oferecidos pela empresa contribuíram para o seu crescimento profissional, com somente um funcionário, $3,85 \%$, não muito certo disso.

De acordo com Invernizzi (2000), registra-se aumento dos investimentos em treinamentos nas empresas e, para a grande maioria dos trabalhadores, a habilitação técnica ocorre sob um novo enfoque, que sintetiza o tradicional treinamento no trabalho e em cursos curtos, e destacase ainda a ampla difusão dos treinamentos comportamentais, direcionados a toda a força de trabalho.

Quanto à avaliação que fazem do programa de educação de que participaram na empresa, destacam-se, entre os pontos positivos, respostas como crescimento, desenvolvimento, aprendizado e conhecimento. Ainda 42,30\% dos funcionários entrevistados não viram pontos negativos nos programas de educação de que participaram; 19,23\% comentaram a falta de acompanhamento posterior, a falta de continuidade; $15,39 \%$ criticaram a pouca quantidade de treinamentos e o fato de poucos terem oportunidades; $11,54 \%$ apontaram problemas de carga horária, organização e formatos dos treinamentos; e 7,69\% dos entrevistados falaram da dificuldade na aplicabilidade, ao aliar teoria e prática. Um dos pontos negativos citados, 3,85\%, também diz respeito à pouca divulgação interna.

Houve uma unanimidade de posicionamento dos funcionários em relação à pergunta sobre se o que aprenderam na empresa pode ser usado em outras situações de trabalho fora dela. Nesse caso, as respostas foram $100 \%$ positivas. 
A expectativa dos funcionários, ao participarem desses cursos, era claramente de agregar conhecimentos, aprender e melhorar profissionalmente, conforme respondido por $61,54 \%$ dos funcionários entrevistados. Somente $7,69 \%$ declararam frustração com suas expectativas sobre os cursos quanto a pôr em prática o que aprenderam. O percentual restante, $30,77 \%$, foram respostas vagas a respeito do assunto.

Com relação à trajetória profissional, 30,77\% dos funcionários entrevistados afirmam categoricamente que foi boa; $26,93 \%$ comentaram claramente a respeito de crescimento e evolução profissional; e 38,46\% citaram as promoções que tiveram em sua trajetória na empresa; 3,84\% a classificaram como um desafio. No geral, 80,77\% deram respostas positivas a respeito da questão; 7,69\% responderam ser a sua trajetória coerente e calculada; e 11,54\% acreditam que suas trajetórias foram longas e lentas e que poderiam ter sido melhores. Portanto, o nível de satisfação quanto a esse aspecto é aparentemente alto.

$\mathrm{E}$, finalmente, no tocante às próprias expectativas com relação à carreira, 15,38\% dos funcionários declararam não ter nenhuma expectativa ao ingressar no quadro da empresa; 7,69\% desejavam apenas permanecer na empresa; $11,54 \%$ almejavam a gerência; e 65,39\%, de uma forma ou outra, comentaram sobre expectativas de crescimento. Desse total, $23,08 \%$ dos entrevistados explicitaram reconhecer na empresa abertura e oportunidades. Somente $7,69 \%$ dos entrevistados nunca foram promovidos; $38,46 \%$ foram promovidos mais de três vezes; e 7,69\% iniciaram pelo nível mais baixo da hierarquia e galgaram todos os cargos, chegando ao segundo posto mais alto da loja, a supervisão, ou seja, passaram por todos os outros cargos e tiveram todas as promoções possíveis. Talvez isso explique o alto nível de satisfação com as próprias trajetórias, visto que a maioria almejava de fato o crescimento em suas expectativas.

Para a empresa, é clara a ideia de que, no competitivo mercado atual, as organizações precisam ser flexíveis, ter capacidade de adaptação, ter a mudança como valor e gerar processos internos com agilidade e custos otimizados, assim:

Viabilizar uma escola corporativa está relacionado com as crenças e os valores da organização. $\mathrm{Na}$ missão da Leader, o funcionário consta como fundamental para o seu negócio. Sua visão é crescer com solidez e percepção compartilhada, proporcionando o desenvolvimento pessoal e profissional de nossa equipe. Nada mais sólido para o crescimento do que compartilhar as 
estratégias, dar foco, investir na educação da equipe, buscando a cada dia patamares superiores de performances.

A Escola Leader de Varejo (ELEVAR) nasceu então da crença de que nossa equipe é o nosso maior diferencial competitivo e que precisamos continuamente investir na preparação do futuro e nas novas exigências do mercado globalizado (GOUVÊEA, 2004, p. 139-140).

Essa concepção da empresa vai ao encontro, de fato, do conceito de educação corporativa, que, segundo Meister (1999), é uma iniciativa organizacional que visa a garantir um processo contínuo e estruturado de aprendizagem vinculada a objetivos estratégicos, de modo a alinhar os processos de educação de funcionários às estratégias da empresa. Aqui, como diz a autora, a própria empresa cria sua escola ou universidade (UC) para garantir uma educação sob medida para os funcionários, o que se confirma inclusive nas entrevistas realizadas com os funcionários a respeito dos objetivos dos cursos de que participaram, pois eles afirmaram que, de fato, os treinamentos e cursos de que participam são todos voltados para o trabalho que realizam, adequados ao papel que eles têm de cumprir.

Nessa mesma vertente, quando a empresa diz almejar "compartilhar conhecimentos", algo descrito na missão da escola corporativa da Leader Magazine, não podemos deixar de nos referir à máxima da Teoria do Capital Intelectual de Nonaka e Takeuchi (1997), segundo a qual o conhecimento tácito, o talento individual de cada um, deve ser compartilhado na empresa para o aumento de sua competitividade. A propalada "Gestão do Conhecimento" também afirma que é necessário sistematizar esse conhecimento para que nada se perca na organização (SVEIBY, 1998).

Também em Gouvêa (2004, p. 139), deparamo-nos com a ideia de fazer "com que a equipe tenha a estratégia no sangue (...)", porque, para as empresas, hoje, em virtude do competitivo mercado, aumentam as exigências aos trabalhadores, o que Santos (2005) analisa criticamente como uma contraposição ao caráter operativo do trabalhador no taylorismo-fordismo, enfatizando-se agora a dimensão cognitivo-afetiva desse trabalhador, elemento também ratificado na fala de um funcionário que comenta sair sempre muito comprometido dos cursos.

Para alcançar as metas de crescimento, a empresa também vislumbrou "transformar os processos de treinamento e desenvolvimento 
(T\&D) em efetivos resultados para a prática empresarial, que era urgente conciliar o treinamento com a prática" (GOUVÊA, 2004, p. 140), o que, nas palavras de Éboli (2004), demonstra uma das características da educação corporativa: "A migração do T\&D tradicional para a Educação Corporativa ganhou foco e força estratégica, evidenciando-se como um dos pilares de uma gestão empresarial bem sucedida" (ÉBOLI, 2004, p. 38).

Para Laval (2004), todas as instituições, muito além da economia, foram afetadas, incluindo a instituição da subjetividade humana: o neoliberalismo visa à eliminação de toda "rigidez", inclusive psíquica, em nome da adaptação às situações mais variadas que o indivíduo encontra, tanto no seu trabalho quanto na sua existência. E Antunes e Alves (2004, p. 344) enfatizam:

Desde a sua origem, o modo capitalista de produção pressupõe um envolvimento operário, ou seja, formas de captura da subjetividade operária pelo capital, ou, mais precisamente, da sua subsunção à lógica do capital (observando que o termo "subsunção" não é meramente "submissão" ou "subordinação", uma vez que possui um conteúdo dialético - mas é algo que precisa ser reiteradamente afirmado). O que muda é a forma de implicação do elemento subjetivo na produção do capital, que, sob o taylorismo/fordismo, ainda era meramente formal e com o toyotismo tende a ser real, com o capital buscando capturar a subjetividade operária de modo integral. (ANTUNES; ALVES, 2004, p. 344)

Ao forjar a mão de obra para o mercado, a educação corporativa reproduz um comportamento de submissão, que Manangão (2003) chama de sujeição ideológica, que serve à proliferação de práticas que sustentam o pensamento oficial do momento histórico-político-econômico atual: o pensamento neoliberal. Se compreendermos a educação corporativa, segundo Meister (1999), como um guarda-chuva estratégico para o desenvolvimento e a educação de funcionários, clientes e fornecedores, e entendendo que o diferencial decisivo de competitividade reside no nível de capacitação de todos esses, e até mesmo da comunidade onde atuam, podemos diretamente vincular essa percepção a alguns programas mantidos pela Leader Magazine.

Segundo Gouvêa (2004, p. 146-147), esses programas abrangem $\mathrm{o}$ atendimento social, que se refere às atividades que proporcionem a ampliação da qualidade de vida, informação de direitos e deveres sociais, 
educação em saúde, projetos de preparação para o mercado, com o objetivo de geração de emprego e renda e administração dos recursos financeiros para familiares de funcionários e comunidades carentes e ainda projetos de voluntariado, oferecendo a oportunidade de toda a empresa exercitar a cidadania, proporcionando o desenvolvimento da consciência social e a participação na transformação da realidade de instituições e comunidades. "A empresa doa horas de trabalho" para que seus funcionários voluntários desenvolvam atividades em instituições e/ou comunidades carentes.

Em seu estudo sobre as novas formas de trabalho e as tendências dos últimos vinte anos, Invernizzi (2000, p. 52) aponta aspectos também confirmados nas entrevistas:

Benefícios que melhoram a qualidade de vida do trabalhador e de sua família e que estão condicionados ao cumprimento de metas por parte do coletivo (...) atuam como recompensas materiais pelo compromisso do trabalhador com a empresa. A política de benefícios tende a envolver a família do trabalhador no incentivo ao comprometimento dele. (INVERNIZZI, 2000, p. 52)

Segundo Manangão (2003, p. 68), essa "cidadania corporativa" serve para as organizações justificarem sua influência sobre as comunidades do seu entorno, ampliando a atuação da educação corporativa para além de seus muros. Em seus estudos em torno dessa temática, Ribas (2003), numa análise crítica, comenta que a questão da parceria e de ações sociais desenvolvidas por empresas vão além da filantropia, tornando-se fator de marketing e de competitividade, o que de fato também foi relatado como um dos resultados da ELEVAR, em Gouvêa (2004, p. 147):

A partir da experiência que vimos desenvolvendo na Leader, fica fácil perceber os resultados alcançados (...) Os resultados têm sido brilhantes e podemos destacar desenvolvimento e fortalecimento do espírito de equipe, consolidação do sentimento de valorização da empresa, reconhecimento da contribuição recebida por parte das instituições, reconhecimento de mídia espontânea (GOUVÊA, 2004, p. 147).

Na conclusão de Santos (2004, p. 9), constatamos que, de fato, “a gestão de recursos humanos, orientada pela ótica hegemônica, muito tem se esforçado por construir esse espírito adesista no âmbito interno das organizações", constituindo-se como uma tentativa de controle da 
subjetividade, aqui demonstrada pelos funcionários ao explicarem suas expectativas: ao participar dos treinamentos, todos esperavam corresponder ao que a empresa esperava deles, além de agregar conhecimentos, aprender e melhorar profissionalmente, conforme respondido por $61,54 \%$ dos participantes.

De fato, de acordo com Alves (1997), com o advento de novos processos organizacionais, o trabalhador se vê condicionado a desenvolver competências exigidas pelo mercado de trabalho, na tentativa de manter-se em um espaço em constante mutação. A empresa, por sua vez, diz Rodrigues (1998), se empenha em projetos pedagógicos que visam a adaptar ou conformar o trabalhador no âmbito psicofísico, intelectual e emocional, às bases organizacionais da produção.

Quanto à avaliação que fazem do programa de educação de que participaram na empresa, destacam-se, entre os pontos positivos, respostas como crescimento, desenvolvimento, aprendizado e conhecimento e, como pontos negativos, são ressaltadas a questão da pouca quantidade de cursos oferecidos e a falta de continuidade e acompanhamento após sua realização, o que, na prática, acontece com os treinamentos pontuais oferecidos.

No material fornecido pela Leader Magazine a respeito de sua cultura organizacional e da implantação da ELEVAR, a empresa explicita que, na sua concepção, a melhor maneira de desenvolver as pessoas é sendo exigente com seu desempenho e conduta, e acredita ser fundamental reconhecer o mérito de cada um como um sistema justo de conduzir os negócios e produzir resultados, por isso avalia e recompensa os funcionários com base nesses critérios. Essa meritocracia da sociedade capitalista vem sendo criticada por Frigotto (1984), por ser uma lógica cruel com os funcionários, estimulados pelas atuais transformações do mundo do trabalho a uma competitividade individual, à qual se submetem em função da propalada empregabilidade.

De acordo com Invernizzi (2000), as pesquisas, em todos os setores, apontam a relevância dada pelos empresários a atitudes pessoais e comportamentais como responsabilidade, envolvimento, cooperação, disponibilidade e iniciativa, e os pesquisadores tendem a coincidir em apontar que essas novas atitudes se tornaram tão relevantes quanto as habilidades técnicas para desenvolver o trabalho nos processos produtivos reestruturados. 


\section{Considerações finais}

No tocante à educação corporativa, interessa discutir o movimento da relação entre trabalho e educação que vai se consolidar nesse modelo educacional e, assim, por meio da pesquisa, foram tecidas algumas considerações a respeito do fenômeno da educação corporativa e de sua implantação de fato: o discurso e a prática.

Este estudo nos possibilitou concluir que a Leader Magazine tem implantada uma política formal de educação corporativa na teoria, mas empreende ações isoladas e pontuais de treinamento na prática. Embora a proposta de educação corporativa esteja voltada eminentemente para a formação em função dos objetivos estratégicos da empresa e do mercado, os funcionários participantes desse processo não o percebem dessa maneira, na realidade, desconhecem a educação corporativa como um modelo diferenciado e encaram as atividades da empresa como cursos e treinamentos e, na avaliação deles, sujeitos e objetos desse processo, acreditam que a educação corporativa também contribui para o seu crescimento pessoal e profissional.

Constata-se ainda que, na prática, a ELEVAR (Escola Leader de Varejo), criada na empresa sob a ótica da educação corporativa, atendeu apenas a alguns segmentos de seus funcionários, sobretudo os de níveis hierárquicos mais elevados. Essa segregação traz a nítida lembrança da escola dual, privilegiando alguns poucos e reforçando a perpetuação de aspectos do neoliberalismo presentes no discurso hegemônico.

Para concluir, é relevante destacar que as relações entre o mundo do trabalho e o mundo da educação parecem estar cada vez mais entrelaçadas, perdendo os limites que até então identificavam cada área de atuação. Como enfrentar o desafio de acompanhar as transformações ocorridas na base da produção e ainda manter o caráter crítico e emancipador da educação? Como construir uma educação profissional de qualidade e com competência, mas que contribua para a melhoria da qualidade de vida dos trabalhadores, e não apenas para o aumento dos lucros e da exploração do trabalho? A visão é de que deverá ser entendida e reavaliada a associação educação e trabalho em todos os âmbitos, considerando o seu papel a desempenhar e o objetivo da construção de um novo cenário para o país, pois somente com a sensibilização e a atenção de todos para a importância da formação humana, técnica e profissional, do entendimen- 
to do homem enquanto ser integral, é que teremos possibilidades de construir uma sociedade menos desigual.

\section{Notas}

${ }^{1}$ Programa de incentivo a parcerias e ao voluntariado. Para detalhes, ver http://amigosdaescola.globo.com.

${ }^{2}$ Grifos da autora, numa alusão crítica ao termo utilizado ao se tratar da Teoria do Capital Humano.

3 A Leader Magazine é uma empresa de base familiar, com sede em Niterói, estado do Rio de Janeiro, e atualmente tem 30 lojas e cerca de 2600 funcionários. Para mais detalhes sobre a empresa, ver www.leadermagazine.com.br.

\section{Referências bibliográficas}

ANTUNES, R.; ALVES,G. As mutações no mundo do trabalho na era da mundialização do capital. Educação e Sociedade, Campinas, v. 25, n. 87, maio/ago. 2004.

ARANHA, M. L.A. História da Educação. São Paulo: Moderna, 1989.

BIANCHETTI, L. Da chave de fenda ao laptop: Tecnologia digital e novas qualificações desafios à educação. Petrópolis/RJ: Vozes, 2001.

BIANCHETTI, L. In/exclusão no processo de qualificação profissional: Educação Corporativa, novos protagonistas e novos loci espaço-temporais de formação dos trabalhadores. 2005. mimeo. Trabalho apresentado no Congresso da Universidade de Aveiro, Portugal, maio de 2005.

BIANCHETTI, L. A globalização econômica e os desafios à formação profissional. Boletim Técnico do Senac, maio/agosto, 1996.

BIANCHET'TI, L. O modelo das competências profissionais no mundo do trabalho e na educação: implicações para o currículo. Boletim Técnico do SENAC, set/dez, 2001.

EBOLI, Marisa. Educação corporativa no Brasil. Mitos e verdades. São Paulo: Gente, 2004. FIDALGO F. A formação profissional negociada. França e Brasil, anos 90. São Paulo: A. Garibaldi, 1999.

FRIGOTTO, G. A produtividade da escola improdutiva - Um (re) Exame das Relações entre Educação e Estrutura Econômico-Social Capitalista. São Paulo: Cortez, 1984.

FRIGOTTO, G. A educação e a crise do capitalismo real. São Paulo: Cortez, 1995.

GOUVÊA, S. Caso Leader Magazine. In: MUNDIM, A.P.F., RICARDO, E.J. (Orgs.). Educação Corporativa: fundamentos e práticas. Rio de Janeiro: Qualitimark, 2004.

HARVEY, D. Condição pós-moderna (uma pesquisa sobre as origens da mudança cultura), Trad. Adail Ubirajara Sobral e Maria Stela Gonçalves. São Paulo: Loyola, 1992.

HOBSBAWM, Eric J. Era dos Extremos: O breve século XX: 1914-1991. São Paulo: Companhia das Letras, 1995.

INVERNIZZI, N. Qualificação e novas formas de controle da força de trabalho no processo de reestruturação da indústria brasileira: tendências dos últimos vinte anos. In: Reunião anual da ANPED, 2000, Caxambu, MG. Trabalho \& Crítica. GT 
Trabalho e Educação da ANPED. São Leopoldo, RS: Unisinos, v. 2. p. 63-78, 2000.

LAVAL, C. A Escola não é uma empresa. O neo-liberalismo em ataque ao ensino público. Londrina: Planta, 2004.

MANANGÃO, K.C.Z. Universidade Corporativa: Um mecanismo do aparelho ideológico educativo. Dissertação (Mestrado em Educação). Universidade Católica de Petrópolis. Petrópolis: UCP, 2003.

MEISTER, J. Educação corporativa. São Paulo: Makron Books, 1999.

NONAKA, I.; TAKEUCHI, H. Criação de Conbecimento na Empresa: como as Empresas japonesas Geram a Dinâmica da Inovação. Rio de Janeiro: Campus, 1997.

OLIVEIRA, R. A Teoria do Capital Humano e a Educação Profissional Brasileira. Boletim Técnico do SENAC, v. 27, n. 1, p. 27-37, jan/abr., 2001.

QUARTIERO, E.; BIANCHETTI, L. (Org). Educaşão Corporativa: mundo do trabalho e do conhecimento: aproximações. São Paulo: Cortez, 2005.

RIBAS, N. Parceria empresa/ escolas públicas: Problema ou solução? Dissertação (Mestrado em Educação). Universidade Federal de Juiz de Fora, Juiz de Fora, 2003.

RODRIGUES, J. Moderno Príncipe Industrial: O pensamento pedagógico da Confederação Nacional da Indústria. Campinas, SP: Autores Associados, 1998.

SANTOS, A.F.T. Teoria do Capital Intelectual e Teoria do Capital Humano: Estado, Capital e Trabalho na política educacional em dois momentos do processo de acumulação. In: 27a Reunião anual da ANPEd, 2004, Caxambu- MG. Anais da 27 a Reunião anual da ANPEd, 2004.

SCHULTZ, T. O Capital Humano. Rio de Janeiro: Zahar, 1973.

SVEIBY, C. E. A nova riqueza das organiz̧ações. Rio de Janeiro: Campus, 1998.

VIANNA, M.A.F. Universidade corporativa - histórico. Disponível em <http://www.institutomvc.com.br/univcorp.htm\#Visa>. Acesso em 8/7/2004.

Endereço para correspondência:

Rua Dr. Albino Pereira, 588

São Francisco

24365-170

Niterói - RJ

Data de recebimento: $10 / 12 / 2008$

Data de aprovação: 14/01/2010 